\title{
Nortriptyline plus lithium increased time to relapse in unipolar depressed patients who responded to electroconvulsive therapy
}

Sackeim HA, Haskett RF, Mulsant BH, et al. Continuation pharmacotherapy in the prevention of relapse following electroconvulsive therapy: a randomized controlled trial.JAMA 2001 Mar 14;285:1299-307.

QUESTION: In patients with unipolar major depression who respond to electroconvulsive therapy (ECT), is nortriptyline hydrochloride or nortriptyline plus lithium carbonate better for preventing relapse?

\section{Design}

Randomised (allocation concealed*), blinded (clinicians, outcome assessors, and data analysts)*, placebo controlled trial with 24 weeks of follow up.

\section{Setting}

2 university based hospitals and 1 private psychiatric hospital in New Jersey, Iowa, and Pennsylvania, USA

\section{Patients}

84 patients (mean age 57 y, $67 \%$ women) who had unipolar major depression, had had $\geqslant 60 \%$ reduction in Hamilton Depression Rating Scale scores after ECT, with a maximum score of 10 at 2 days and 4-8 days; and did not use psychotropic medication. Exclusion criteria were medical contraindications to nortriptyline or lithium. Follow up was $87 \%$.

\section{Intervention}

After stratification according to type of index episode (psychotic, medication resistant non-psychotic, or nonpsychotic without medication resistance), patients were allocated to 1 of 3 groups: nortriptyline $(n=27)$, nortriptyline plus lithium $(\mathrm{n}=28)$, or matching placebo $(\mathrm{n}=29)$. The target concentrations were $75-125 \mathrm{ng} / \mathrm{ml}$ for nortriptyline (given in $25 \mathrm{mg}$ pills) and $0.5-0.9$ $\mathrm{mmol} / \mathrm{l}$ for lithium (given in $300 \mathrm{mg}$ pills).

\section{Main outcome measure}

Time to relapse.

\section{Main results}

Time to relapse was longer in the nortriptyline $(\mathrm{p}=0.01)$ and the nortriptyline plus lithium $(\mathrm{p}<0.001)$ groups than in the placebo group. The nortriptyline plus lithium group also had a longer time to relapse than the nortriptyline alone group $(p=0.04)$. At 24 weeks, fewer patients in the nortriptyline plus lithium group than in the placebo group relapsed $\{p=0.001\}+$ relapse rates did not differ between placebo and nortriptyline alone or between nortriptyline plus lithium and nortriptyline alone (table).

\section{Conclusion}

In unipolar depressed patients who responded to electroconvulsive therapy, nortriptyline plus lithium reduced relapses and led to a longer relapse free period than did nortriptyline alone or placebo.

*See glossary.

tp Value calculated from data in article.

Sources of funding: National Institute of Mental Health.

Lithium carbonate supplied by Solvay Pharmaceuticals Inc, Mariette, GA, and ECT therapy devices donated by the MECTA

Corporation.

For correspondence: Dr H A Sackeim, Department of Biological Psychiatry, New York State Psychiatric Institute, 1051 Riverside Drive, New York, NY 10032, USA. Fax +1212543 5854

Relapse rates for nortriptyline plus lithium v nortriptyline alone v placebo for depressed patients who responded to electroconvulsive therapy:

\begin{tabular}{|c|c|c|c|}
\hline Comparisons at 24 weeks & Event rates & $\operatorname{RRR}(95 \% \mathrm{Cl})$ & NNT (Cl) \\
\hline Nortriptyline $v$ placebo & $60 \% \vee 84 \%$ & $29 \%(-1$ to 53$)$ & Not significant \\
\hline Nortriptyline + lithium $v$ placebo & $39 \%$ v $84 \%$ & $53 \%(25$ to 74$)$ & $3(2$ to 6$)$ \\
\hline $\begin{array}{l}\text { Nortriptyline + lithium } v \text { nortriptyline } \\
\text { alone }\end{array}$ & $39 \%$ v $60 \%$ & $35 \%(-16$ to 65$)$ & Not significant \\
\hline
\end{tabular}

\section{COMMENTARY}

Many depressed patients, especially those who are medication resistant, relapse after successful ECT despite continuation treatment with antidepressant drugs. The study by Sackeim et al suggests that patients with unipolar major depression who respond to ECT should best receive a lithium plus nortriptyline combination as continuation treatment. To this extent, the consideration of continuation ECT may be delayed or averted.

About $30-60 \%$ of depressed patients relapse within 6 months of ECT unless they receive continuation antidepressant pharmacotherapy. ${ }^{1}$ The 24 week placebo relapse rate in this study was higher (84\%), suggesting that the sample was biased towards poorer outcome. The findings of this study by Sackeim $e t$ al are hence more applicable to patients with a poor prognosis, such as those who are severely ill or medication resistant, for whom ECT may have been prescribed as a (relatively) last resort. The lithium plus nortriptyline combination may carry no advantages over nortriptyline alone in patients who are less severely ill, those who are not medication resistant, and those to whom ECT is prescribed as an early choice.

In this study, all but 1 instance of relapse with the lithium plus nortriptyline combination occurred within 5 weeks of ECT termination; in contrast, relapse continued throughout the 24 week study with placebo or nortriptyline alone. Sackeim et al therefore suggested that the earlier institution of the lithium-nortriptyline combination, such as at the start of the ECT course, may result in an earlier onset of efficacy of the combination; the early relapses may thereby be prevented. This suggestion is unsupported but is worth researching. Sackeim $e t$ al also suggested that the early relapses may be reduced if ECT is tapered and withdrawn, much as drugs are tapered and withdrawn after successful pharmacotherapy. This suggestion, also unsupported, is also worth researching. Only the study by Barton $e t$ al has investigated the issue;" although the authors concluded that prescribing 2 extra ECT sessions at the end of a course has no advantages, their study was methodologically weak, and the data were capable of being otherwise interpreted.

Chittaranjan Andrade, MD National Institute of Mental Health and Neurosciences Bangalore, India

1 Abrams R. Electroconvulsive therapy. Third edition. New York: Oxford University Press, 1997;190.

2 Barton JL, Mehta S, Snaith RP. The prophylactic value of extra ECT in depressive illness. Acta Psychiatr Scand 1973;49:386-92. 